\title{
ATMOSPHERIC SO, MEASUREMENTS AT THE BRAZILIAN ANTARCTIC STATION
}

\author{
http://dx.doi.org/10.4322/apa.2014.021 \\ Ericka Voss Chagas Mariano ${ }^{1, *}$, Neusa Maria Paes Leme², Plinio Carlos Alvalá ${ }^{3}$ \\ 1Programa de Pós-Graduação em Geofísica Espacial, \\ Instituto Nacional de Pesquisas Espaciais - INPE, São José dos Campos, SP, Brazil \\ ${ }^{2}$ Centro Regional do Nordeste, Instituto Nacional de Pesquisas Espaciais - CRN/INPE, Natal, RN, Brazil \\ ${ }^{3}$ Centro de Ciência do Sistema Terrestre - CCST, Instituto Nacional de Pesquisas Espaciais - INPE, São José dos Campos, SP, Brazil \\ *e-mail: erickavoss@gmail.com
}

\begin{abstract}
For a better comprehension of the atmospheric chemical and radiative properties, it is necessary to understand the behaviour of trace gases and aerosols; some of these gas types have not been deeply studied. Sulphur dioxide $\left(\mathrm{SO}_{2}\right)$ is found in the troposphere, as a result of both natural and anthropogenic emissions. To study the behaviour of this gas in the Antarctic continent, the data collected by the Brewer Spectrophotometer installed in the Brazilian Antarctic Station Comandante Ferraz $\left(62^{\circ} 05^{\prime} \mathrm{S}\right.$ and $\left.58^{\circ} 24^{\prime} \mathrm{W}\right)$ was used. With this ground-based instrument, the total column of $\mathrm{SO}_{2}$ was measured from the beginning of springtime, to the start of summer, during the years 2003 to 2009. It was possible to observe that the total columns of $\mathrm{SO}_{2}$ did not show any differences in the time of the development of the ozone hole, as compared to other periods. The main sources of anthropogenic $\mathrm{SO}_{2}$ pollution in this region are the generation of energy, the operations with ships, and the burning of garbage, being a punctual impact. The natural generation of $\mathrm{SO}_{2}$ in this region is mainly related to the conversion of DMS (dimethyl sulfide) emitted by the ocean. In a few days, the $\mathrm{SO}_{2}$ total column exceeded the values considered normal for remote regions (>2 UD), and these high concentrations must have their sources identified and monitored.
\end{abstract}

Keywords: atmospheric chemistry, sulfur dioxide, Brewer Spectrophotometer

\section{Introduction}

Antarctica is the coldest, windiest, and driest continent on Earth, with a remote location far from the major centres of population. Yet as one of the two heat sinks in the global climate system it plays a crucial role in the general circulation of the atmosphere and has a profound effect on the atmospheric and oceanic conditions across the Southern Hemisphere (Turner, 2003).

The study of the changes in the atmospheric $\mathrm{SO}_{2}$ concentration is important because this gas has effects in the atmospheric chemistry and in the radiation field, with climatic consequences. In this case, the climate and atmosphere research requires continuous $\mathrm{SO}_{2}$ observations (Fioletov et al., 1998). $\mathrm{SO}_{2}$ is emitted in the atmosphere as a result of natural phenomena as well as anthropogenic activities, such as fossil fuel combustion, volcanic eruptions, biomass burning and the oxidation of organic materials in soil and of dimethyl sulfide (DMS) over oceans. The sulfur dioxide $\left(\mathrm{SO}_{2}\right)$ found in the Antarctic region is mostly originated from DMS. $\mathrm{SO}_{2}$ also plays an important role in cloud formation physics, leading to clouds of high reflectivity. In the stratosphere $\mathrm{SO}_{2}$ is also oxidized and combines with water to form sulfate aerosols (Bekki, 1995). These aerosols scatter solar radiation and absorb long-wave radiation, causing heating in the stratospheric region and net cooling at the Earth's surface (Georgoulias et al., 2009). 
In regions where the air pollution is small, the $\mathrm{SO}_{2}$ concentration is lower than $2 \mathrm{DU}$, whereas in polluted regions this value reaches 4 to $6 \mathrm{DU}$ (Fioletov et al., 1998), and in extreme cases reaching $20 \mathrm{DU}$ or higher, as in the case of volcanic eruption events (De Muer \& De Backer, 1992). Cappellani and Bieli (1994) state that $\mathrm{SO}_{2}$ in the air vertical column is concentrated in the low troposphere, mainly trapped in the mixture layer. De Muer \& De Backer (1992) say that, occasionally, higher amounts of $\mathrm{SO}_{2}$ in the stratosphere, resulting from volcanic eruptions, may be observed. However, the conclusions presented by these authors work show that, in general, almost every $\mathrm{SO}_{2}$ in the vertical is found in the lower troposphere.

Several methods have been developed for measuring not only near surface concentrations but also the total atmospheric content using ground-based instruments (Georgoulias et al., 2009). The Brewer spectrophotometer was developed at the beginning of the 1980 s to precisely measure ozone $\left(\mathrm{O}_{3}\right)$ (Kerr et al., 1981), and also measures sulphur dioxide $\left(\mathrm{SO}_{2}\right)$, nitrogen dioxide $\left(\mathrm{NO}_{2}\right)$ and spectral irradiance in the ultraviolet band. This instrument is widely used by the Global Atmosphere Watch (GAW) program of the World Meteorological Organization (WMO) to measure the $\mathrm{O}_{3}$ columns. Today, there are more than 180 instruments installed around the globe (Fioletov et al., 2005).

\section{Materials and Methods}

\section{Brewer spectrophotometer}

The Brewer spectrophotometer is a ground based instrument which makes measurements of solar radiation, allowing the measurement of the total column of the following atmospheric gases: ozone $\left(\mathrm{O}_{3}\right)$, sulphur dioxide $\left(\mathrm{SO}_{2}\right)$ and nitrogen dioxide $\left(\mathrm{NO}_{2}\right)$. It can also measure the solar global radiation in the band ultraviolet $\mathrm{B}$ (UVB). This instrument uses the Dobson unit (DU) to express the total columns of $\mathrm{O}_{3}, \mathrm{NO}_{2}$ and $\mathrm{SO}_{2}$.

The Brewer spectrophotometer is totally automated and made up of three parts: tripod, tracker (a system that traces the sun) and the spectrophotometer itself. The instrument contains a microprocessor, responsible for the equipment's internal operations. This microprocessor is connected to a computer that, through the Brewer software, controls the functioning of the instrument, and the data reduction and storage. The five wavelengths of operation are located in the ultraviolet band of the $\mathrm{O}_{3}$ and $\mathrm{SO}_{2}$ absorption spectrum, which have a strong and variable absorption in this region: $306.3 ; 310 ; 313.5 ; 316.8 ; 320 \mathrm{~nm}$.

The measurement of the total column of an atmospheric gas made by a ground based instrument is based on the principle of absorption of radiation that penetrates a quantity of matter. Surface based methods use radiance measurements of an external source, such as the Sun or the moon, after the radiation had been extinguished, as a result of atmospheric absorption, molecular scattering and aerosol (particle) scattering, all of them dependant on the wavelength (Whitten \& Prasad, 1985).

\section{Data collection and treatment}

The Ozone Laboratory, that belongs to the National Institute for Space Research, has a network of Brewer Spectrophotometers in South America. The data presented here was obtained in the Brazilian Antarctic Station Comandante Ferraz, from 2003 to 2009 through the Direct Sun method, using the direct solar beam as a radiation source. The data collected by the Brewer required reducing in order to be evaluated. This process is undertaken by an analysis program developed specially for the instrument - the Brewer Spectrophotometer B Data Files Analysis Program. This program reads the Brewer files according to the calibration data of each instrument. Since each instrument has a distinct calibration, this stage of the data treatment takes longer to be completed. For the analysis of the data collected for this research, techniques of Descriptive Statistics were used.

\section{Results and Discussion}

It is possible to notice a great variability in the data (Figure 1), including negative results, which are due to the Brewer $\mathrm{SO}_{2}$ algorithm and must be considered corresponding to very low total columns. When the total column increases, on isolated days, it is not likely that this is 


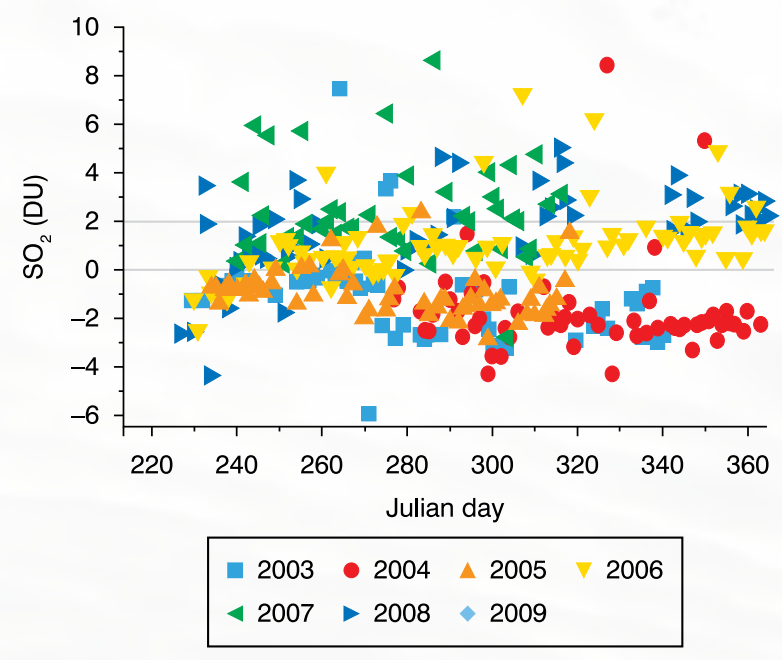

Figure 1. Daily average of the $\mathrm{SO}_{2}$ total column for the Brazilian Antarctic Station from August to December, from 2003 to 2009

Table 1. Annual average of the $\mathrm{SO}_{2}$ total columns for the Brazilian Antarctic station

\begin{tabular}{cc|} 
Year & Average \\
2003 & $-0,9$ \\
2004 & $-1,7$ \\
2005 & $-0,9$ \\
2006 & 0,9 \\
2007 & 2,5 \\
2008 & 1,6 \\
2009 & 3,0 \\
\hline
\end{tabular}

associated with an increase of $\mathrm{SO}_{2}$ in the stratosphere, unless when this is related to volcanic eruptions, which is not the case in this study. In the Antarctic region, the main natural contribution to the maintenance of the $\mathrm{SO}_{2}$ column (even in low concentrations) is the conversion of organic material from the soils, and the oxidation of DMS over the ocean.

It was possible to observe an increase in the average total $\mathrm{SO}_{2}$ column over the years for each annual period evaluated (Table 1). From 2006, the average turned positive. This coincides with the beginning of the construction of the expansion of the station, which may indicate an increase in the emission of pollutants. As the Antarctic region is a remote location, total columns above $2 \mathrm{DU}$ can already be

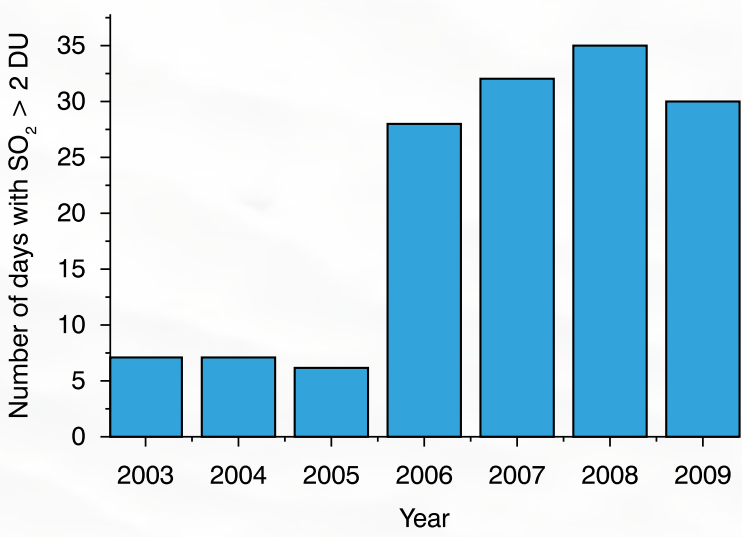

Figure 2. Number of days with $\mathrm{SO}_{2}$ total column higher than 2 Dobson Units DU for the period studied.

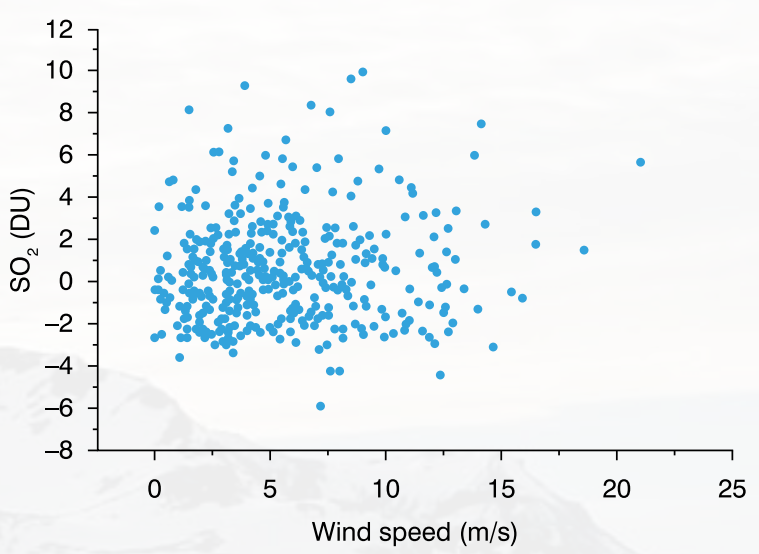

Figure 3. Correlation between the $\mathrm{SO}_{2}$ total column and Wind speed for the studied period.

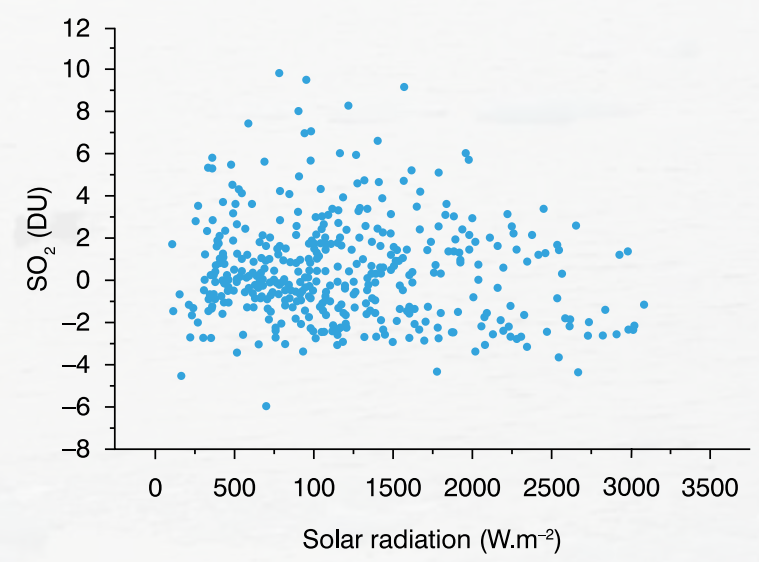

Figure 4. Correlation between the $\mathrm{SO}_{2}$ total column and solar radiation for the studied period. 


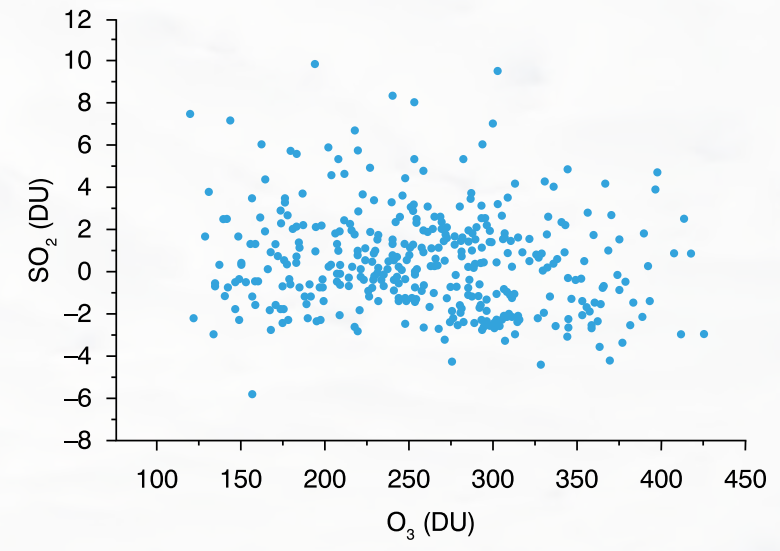

Figure 5. Correlation between the $\mathrm{SO}_{2}$ total column and the $\mathrm{O}_{3}$ total column for the studied period.

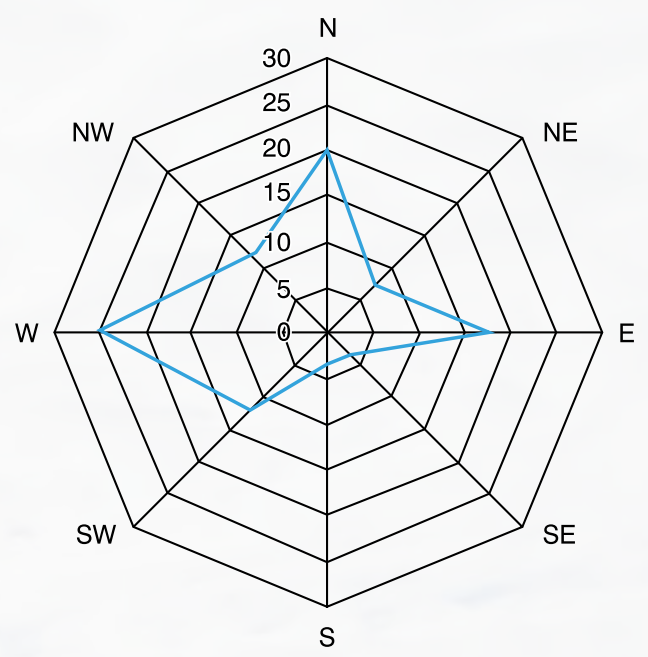

Figure 6. Predominant Wind direction for the days with $\mathrm{SO}_{2}$ higher than 2 Dobson Units.

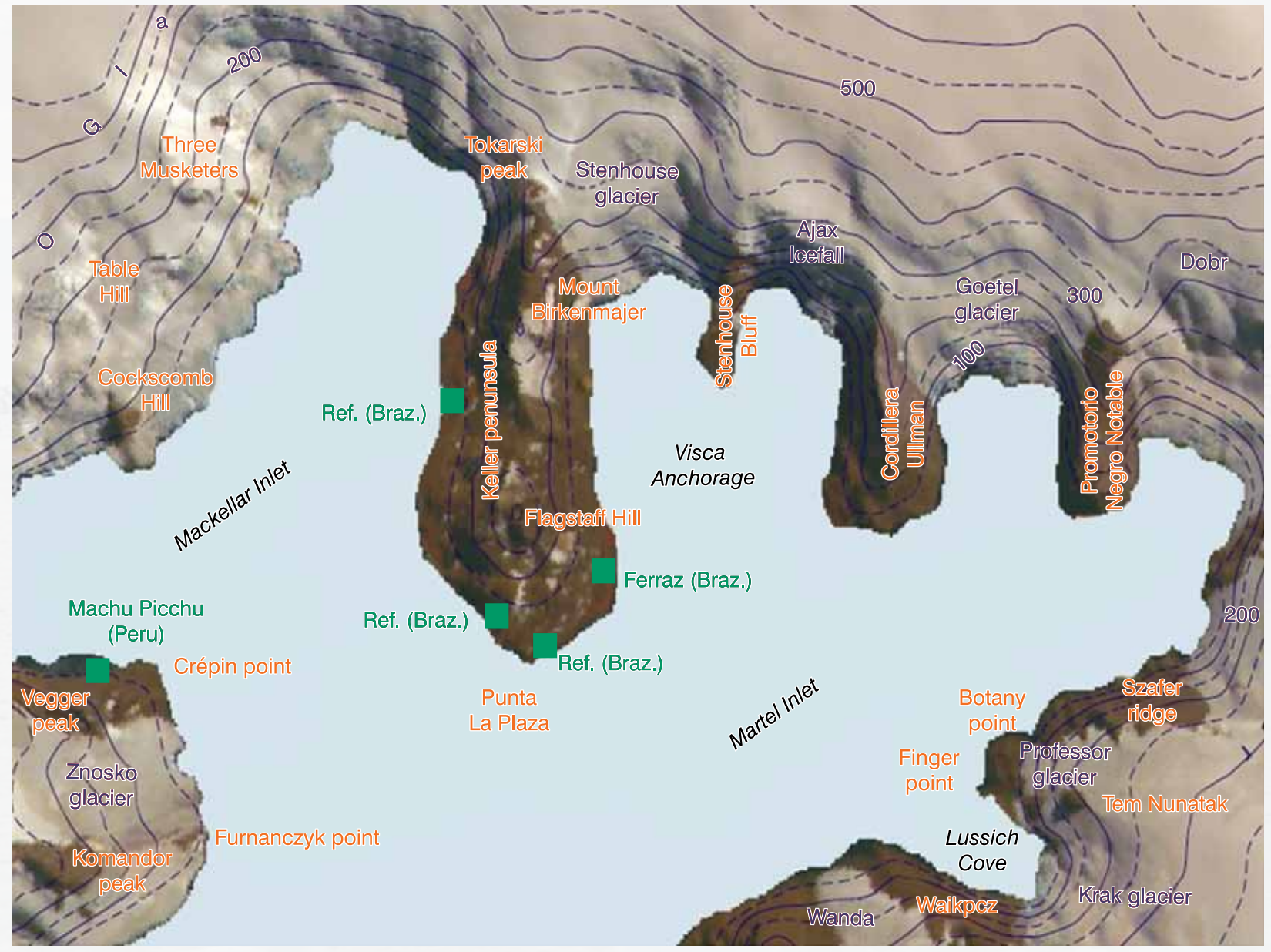

Figure 7. Map of the King George Island, showing the main stations. Adapted from http://hs.pangaea.de/Images/Maps/King George Island/King George Island Map.pdf. 
considered relatively high, taking into account the level of local natural pollution. The maximum value of 9.9 DU was observed in 2007, a rate comparable with that seen in cities like Cubatão, known for its high levels of pollution.

It is possible to see in Figure 2 the increase in the number of days with total column higher than $2 \mathrm{DU}$ from the year 2006. In all years, 145 days were observed with total column above this value, and in 2006 the number of days was more than three times higher than the previous year. In Antarctica, the most significant anthropogenic contributions are related to power generation, operations with ships, and waste burning, being a punctual impact.

When analyzing the graph with the number of days with $\mathrm{SO}_{2}$ higher than $2 \mathrm{DU}$ (Figure 2), it is possible to see that from 2006 this number increased dramatically, possibly due to the expansion of the Antarctic Brazilian station.

With respect to wind speed (Figure 3), a correlation of 0.08 between the observed data was found, i.e., no significant correlation. The same was seen for solar radiation (Figure 4), with a correlation coefficient of -0.10 , indicating a weak correlation. Also, for $\mathrm{O}_{3}$, no significant correlation was found (Figure 5).

Evaluating the wind direction when the total column exceeds 2 DU (Figure 6), it is possible to note that the preferred directions of wind are west, north and east, in that order. Looking at the map with the positioning of the weather station and the Brewer spectrophotometer with respect to the Comandante Ferraz Antarctic Station (Figure 7), it is possible to see that the increase in the total column of $\mathrm{SO}_{2}$ occurs when the wind blows from the Keller Peninsula, the Brazilian station, and the Martel inlet, respectively. The energy generator is adjacent to the station, and the contribution coming from the Martel inlet may be related to operations with ships.

Few studies on the $\mathrm{SO}_{2}$ total column were carried out in Antarctica. Chakrabarty and Peshin (2007) found a pattern in the total column of $\mathrm{SO}_{2}$ different from that found in this study. In the case of the Brazilian station Comandante Ferraz, the data appears more scattered, while at Maitri $\left(70.7^{\circ} \mathrm{S}\right.$ and $\left.11.7^{\circ} \mathrm{E}\right)$ the distribution is approximately normal. They also found a correlation with UV-B radiation, which was not shown by this study.

\section{Conclusions}

$\mathrm{SO}_{2}$ total columns present a somewhat scattered behaviour, which indicates the source as being anthropogenic activities. No correlation was found between $\mathrm{SO}_{2}$ total column with solar radiation, wind speed and $\mathrm{O}_{3}$ total column. Wind direction indicates contribution from the Martel Inlet and the Brazilian Antarctic station. This work is a previous treatment as part of an effort to establish a methodology for the use of $\mathrm{SO}_{2}$ data from the Brewer Spectrophotometer .

\section{Acknowledgments}

This work was partially sponsored by the Brazilian Antarctic Program (PROANTAR/MCT/CNPq process $\mathrm{n}^{\circ} .:$ 52.0182/2006-5), SECIRM, INPE and INCT-APA (Instituto Nacional de Ciência e Tecnologia Antártico de Pesquisas Ambientais, CNPq process n ${ }^{\circ}$ 574018/2008-5 and FAPERJ process $n^{\circ} \mathrm{E}-16 / 170.023 / 2008$ and the technicians Armando Hadano and José Roberto Chagas from INPE, for the support in Antarctica.

\section{References}

Bekki, S. (1995). Oxidation of volcanic $\mathrm{SO}_{2}$ : a sink for stratospheric $\mathrm{OH}$ and $\mathrm{H}_{2} \mathrm{O}$. Geophysical Research Letters, $22(8)$ : 913-6.

Cappellani, E. \& Bielli, A. (1994). Correlation between $\mathrm{SO}_{2}$ and $\mathrm{NO}_{2}$ measured in an atmospheric column by a Brewer spectrophotometer and at ground-level by photochemical techniques. Environmental Monitoring and Assessment, 35(2): 77-84

Chakrabarty, D.K. \& Peshin, S.K. (2007). Effect of stratospheric $\mathrm{O}_{3}$ depletion on tropospheric $\mathrm{SO}_{2}$ column in Antarctica. Journal of Atmospheric and Solar-Terrestrial Physics, 69(12): 1377-87.

De Muer, D. \& De Backer, H. (1992). Revision of 20 years of Dobson total ozone data at Uccle (Belgium) - Fictitious Dobson total ozone trends induced by sulfur dioxide trends. Journal of Geophysical Research, 97(D5): 5921-37. 
Fioletov, V.E.; Griffioen, E.; Kerr, J.B. \& Wardle, D.I. (1998). Influence of volcanic sulfur dioxide on spectral UV irradiance as measured by Brewer spectrophotometers. Geophysical Research Letters, 25(10): 1665-8.

Fioletov, V.E.; Kerr, J.B.; McElroy, C.T.; Wardle, D.I.; Savastiouk, V. \& Grajnar, T.S. (2005). The Brewer Reference Triad. Geophysical Research Letters, 32(20): 1-4.

Georgoulias, A.K.; Balis, D.; Koukouli, M.E.; Meleti, C.; Bais, A. \& Zerefos, C. (2009). A study of the total atmospheric sulfur dioxide load using ground-based measurements and the satellite derived Sulfur Dioxide Index. Atmospheric Environment, 43(9): 1693-701.

Kerr, J.B.; McElroy, C.T. \& Olafson, R.A. (1981). Measurements of ozone with the Brewer spectrophotometer, In: London, J. (ed.). Proceedings of the Quadrennial International Ozone Symposium. Natl. Cent. for Atmos. Res., Boulder, Colo. pp. 74-79,

Turner, J. (2003). The Antarctic climate. In: Holton, J.R.; Curry, J.A. \& Pyle, J.A. (eds.). Encyclopedia of Atmospheric Sciences. Academic Press.

Whitten, R.C. \& Prasad, S.S. (1985). Ozone photochemistry in the stratosphere. In: Whitten, R.C.; Prasad, S.S. (eds.). Ozone in the free atmosphere. New York: Van Nostrand Reinhold. p. 81-122. 